\title{
Analysis of the composition of Iris $x$ hybrida hort. collection of Nikitsky Botanical Gardens - National Scientific Center by valuable decorative and economic-biological features
}

\author{
Alexandra Sheynina*, and Irina Ulanovskaya \\ Federal State Budgetary Institution of Science «The Nikitsky Botanical Gardens - National Scientific \\ Center of the RAS», Yalta, Russian Federation
}

\begin{abstract}
The article presents the results of the analysis of the cultivar composition of the Iris $\times$ hybrida hort. collection of Nikitsky Botanical Gardens according to bloom season and color classification. As a result of the analysis of phenological observations, the average long-term dates of the «beginning of flowering» phase in the conditions of the South Coast of Crimea were determined for all collection cultivars. The definition of the studied cultivars according to the bloom season within the garden groups into early flowering, medium flowering and late flowering has been carried out. Lists of cultivars by color classes are presented. The data obtained can be used in the practice of landscaping resort areas to create long blooming without a break compositions with the inclusion of Iris $\times$ hybrida hort. cultivars from various garden groups. The definition of Iris $\times$ hybrida hort. cultivars of NBS - NSC collection by color classes in accordance with the classification proposed by The American Iris Society was also carried out. Lists of cultivars by color classes are presented. The data obtained can be used by landscape architects to create flower arrangements in specific color spectrum in combination with companion plants.
\end{abstract}

\section{Introduction}

One of the main areas of work of botanical gardens is the preservation of biological diversity. For this purpose, in the Nikitsky Botanical Gardens - National Scientific Center (NBS - NSC), collections of ornamental flowering crops have been created, maintained and increased, on the basis of which introduction and breeding studies are conducted [1-3]. One of such collections is the collection of bearded garden iris (Iris $\times$ hybrida hort.) [4]. In world practice, in recent decades, this culture is one of the most popular and demanded, which is confirmed by numerous studies carried out in different botanical gardens [5-8]. Variety of Iris $\times$ hybrida hort. cultivars from different garden groups allows them to be widely used in various types of flower decoration: from planting on rocky hills to creating large groups on the lawn and mixborders, as well as for cutting $[9,10]$. However, there is a

\footnotetext{
* Corresponding author: flowersnbs@mail.ru
} 
shift in blooming season of Iris $\times$ hybrida hort. in different climatic zones, and a decrease of flower color steadiness to fading, which is expressed in a rapid loss of the color intensity of the flower. The southern coast of Crimea is a zone of dry subtropics of the Mediterranean type. In subtropical conditions, the year is divided not into four seasons, but into two periods: cold and warm. April is taken as the beginning of the warm period, the average monthly temperature of which is close to $10^{\circ} \mathrm{C}$ [11]. Due to these factors, many ornamental flowering crops in the South Coast enter the blooming phase much earlier than in other, more northern regions of Russia.

The date of the beginning of Iris $\times$ hybrida hort.collection formation in the NBS - NSC can be considered the 70s of the last century, when in 1976 Nikolai Antonovich Shelygin first carried out research on garden iris cultivars in the South Coast of Crimea. At the same time, the first results were summed up, as a result of the analysis, it was concluded that the introduction into culture and the use of Iris $\times$ hybrida hort. in the landscaping of the South Coast of Crimea was prospective [12]. Subsequently, the collection of Iris $\times$ hybrida hort. of the Nikitsky Botanical Gardens was in different conditions. Regular stocking of collection funds with new domestic and foreign selection cultivars, possessing various biological and morphological features, was began by Alexander Stanislavovich Krasovsky in the mid-80s and continued by us since 2001. Currently, the collection of Iris $\times$ hybrida hort. in the NBS - NSC includes 300 domestic and foreign cultivars of different years of creation, from different garden groups.

The purpose of this study is to analyze the composition of Iris $\times$ hybrida hort. cultivars of NBS - NSC collection by such features as blooming season in conditions of Southern Coast of Crimea and color class affiliation.

\section{Materials and methods}

The objects of the study were 300 Iris $\times$ hybrida hort. cultivars from the collection of the NBS - NSC. Study of Iris $\times$ hybrida hort cultivar's features was carried out according to generally accepted methods $[13,14]$. Rhythms of growth and development were studied according to the "Methodology for conducting phenological observations in the botanical gardens of the USSR" [15]. The definition of cultivars by flower color classes is given according to the classification adopted by the largest and most authoritative community of garden iris growers in the world, The American Iris Society (AIS) [16].

\section{Results and discussion}

Iris $\times$ hybrida hort. collection of the Nikitsky Botanical Gardens includes 300 cultivars from the main garden groups. The main parameter for various garden classifications in the world is the height of the generative shoot, as well as for some groups such parameters as the size of the flower and the blooming season are additionally taken into account. All studied Iris $\times$ hybrida hort. cultivars of the NBS - NSC collections are relatively divided into three groups according to height: dwarf (up to $40.0 \mathrm{~cm}$ ), medium $(41.0-70.0 \mathrm{~cm}$ ), tall (over $70.0 \mathrm{~cm}$ ). The medium group combines classic cultivars of the intermediate group (with the beginning of blooming season between dwarf and tall) and the border group (blooming simultaneously with tall ones).

Iris $\times$ hybrida hort. cultivars of the NBS - NSC collections are proportioned as follows: 253 cultivars belong to the group of tall bearded irises, 10 cultivars - to the group of medium and 37 - to the group of dwarf ones. Thus, the group of tall cultivars is represented most fully in the collection. 
An important feature for ornamental plants is the season and duration of blooming. Blooming sequence of Iris $\times$ hybrida hort. garden groups is strictly defined, the first to enter the blooming phase are the dwarf cultivars, then the cultivars of the medium group and the cultivars of the tall group complete this process. It should also be noted that within each garden group there are cultivars with different blooming season: early blooming, middle blooming and late blooming.

As a result of the analysis of long-term phenological observations (from 3 to ten years or more, depending on the year when cultivar was introduced into collection), it was determined that the average long-term dates of the bloom beginning of dwarf cultivars on the South Coast of Crimea fall on the second decade of April. Early-bloom cultivars of dwarf irises enter the blooming season from 11 to 14 April. There are 14 such cultivars in the collection of NBS - NSC: 'Blue Pools', 'Bourgeois', 'Carats', 'Dark Vader', 'Indian PowWow', 'Iris Sea', 'Olvia', 'Ornament', 'Pause', 'Ritz', 'Stockholm', 'Terse Verse', 'Vogni Yalty', 'Zoryana'. Cultivars of dwarf irises with middle-bloom season start to bloom from 15 to 19 April, there are 17 such cultivars in the collection: 'Beau', 'Cat's Eye', 'Chanted', 'Demon', 'Double Lament', 'Galleon Gold', 'Inscription', 'Kiwi Slices', 'Krayina Mandarynok', 'LilliBright', 'Little Bev', 'Mrs. Nate Rudolph', 'Pumping' Iron', 'Skip Stitch', 'Snow Season', 'Vechory na Khutori', 'What Again'. Cultivars of dwarf irises with late-bloom season begin to bloom from April 20 to April 24, this group is represented by 6 cultivars: 'El Torito', 'Lace Caper', 'Little Blackfoot', 'Lore', 'Lumalite', 'Magnetic Storm'. The average blooming duration of one dwarf cultivar is 18 days. The total duration of blooming period of cultivars from this group is more than 30 days.

The cultivars of the medium group, according to our data, come into bloom on the South Coast of Crimea in the second decade of April. The average long-term blooming date of cultivars from this group falls in the third decade of April. Early-bloom cultivars begin their blooming between April 24-27 ('Fruit Cocktail', 'Hi', 'Wing My Chimes', 'Zing Me'). Middle-bloom cultivars - from April 28 to May 1 ('Apricot Frosty', 'Hot Fudge', 'Lemon Pop'). Late-bloom cultivars - from May 2 to May 6 ('Blackbeard', 'Devil's Playground', 'Amur Batushka'). The average duration of one cultivar blooming from the medium group is 22 days. The total blooming duration of collection medium cultivars is 46 days.

Then tall cultivars come into bloom, as a rule, it occurs in the first decade of May. Early-bloom cultivars enter the blooming phase from May 1 to May 10. There are 108 such cultivars in the collection of NBS - NSC: 'About Town', 'Apostol', 'Arabian Story', 'Aura Light', 'Ayu-Dug', 'Betty Simon', 'Black Tie Affair', 'Blue Reflection', 'Brazen Beauty', 'Breakers', 'Bronzovy Vek', 'Bygone Era', 'Carl and Sissy', 'Cascadian Rhythm', 'Celebration Song', 'Champagne Elegance', 'Cherry Glen', 'Cherub's Smile', 'Classic Look', 'Coffee Whispers', 'Commando', 'Copatonic', 'Copper and Snow', 'Cozy Calico', 'Cross Current', 'Delta Blues', 'Double Bubble', 'Electrique', 'Emphasis', 'English Charm', 'Excellency', 'Filibuster', 'Fireside Glow', 'Flights of Fancy', 'Fringe Benefits', 'Frosting', 'Going Home', 'Golden Panther', 'Hello Darkness', 'High Class', 'High Master', 'Hollywood Nights', 'Honeymoon Suite', 'Honky Tonk Blues', 'Ironiya Doli', 'Juan Valdez', 'Jumping', 'Jurassic Park', 'Kapriz', 'Katie Pie', 'Kilt Lilt', 'Kind Hearted', 'Lacy Snowflake', 'Lake Placid', 'Latin Lark', 'Limelighter', 'Living Free', 'Loonnaya Raduga', 'Lovely Dawn', 'Magic Wish', 'Martile Rowland', 'Mesmerizer', 'Moroccan Magic', 'Morning Mood', 'Mriya', 'Navajo Blanket', 'Nordica', 'Ocelot', 'Odna Kalina', 'Olympic Challenge', 'Pagan Mirth', 'Picasso Moon', 'Pink Sleigh', 'Play with Fire', 'Quickstep', 'Rancho Rose', 'Rare Treat', 'Revolution', 'Romantic Evening', 'Royal Crusader', 'Santa', 'Secret Melody', 'Silk Romance', 'Skif', 'Skipalong', 'Sky Hooks', 'Sneezy', 'Snowed In', 'Song of Norway', 'Soul Music', 'Stairway to Heaven', 'Staroye Zoloto', 'Stop the Music', 'Sugar Magnolia', 'Superman', 'Svitanok', 'Swedish Modern', 'Syzokryliy Ptakh', 'Tanets Flamingo', 'Teamwork', 'Temple Gold', 'Thin Blue Line', 'Tom Johnson', 'Tuscan Villa', 'Twice Told', 'Victoria Falls', 'Vodogray', 'Zany'. 
Middle-bloom cultivars start to bloom from 11 to 16 May. This group includes 85 cultivars of the collection: 'Acoma', 'African Mahogany', 'Back in Black', 'Before the Storm', 'Beverly Sills', 'Bile Tango', 'Blue Crusader', 'Brazilian Holiday', 'Bright Fire', 'Champagne Waltz', 'Chasing Rainbows', 'Cloud Ballet', 'Color Magician', 'Color Splash', 'Conjuration', 'Cosmic Dance', 'Crystal Gazer', 'Crystal Glitters', 'Dance Hall Dandy', 'Darkside', 'Divine Duchess', 'Draco', 'Dusky Challenger', 'Dynamite', 'Easter Lace', 'Edith Wolford', 'Fiesta Time', 'Fogbound', 'Gay Parasol', 'Ghost Train', 'Golly Gee Whiz', 'Gypsy Caravan', 'High Roller', 'Jean Hoffmeister', 'Lotus Land', 'Lovely Kay', 'Luxury Lace', 'Madame Chéreau', 'Mallory Kay', 'Mallow Dramatic', 'Mary Frances', 'Mulled Wine', 'New Centurion', 'New Leaf', 'Night Attack', 'Night Game', 'Nothing But Net', 'Orchid Tapestry', 'Pink Belle', 'Pledge Allegiance', 'Polet Flamingo', 'Pure-as-The', 'Renaissance Fair', 'River Hawk', 'Riversong', 'Rolling Thunder', 'Scarb Neptuna', 'Seakist', 'Sertse Okeanu', 'Sharpshooter', 'Sierra Grande', 'Silverado', 'Skywalker', 'Snowmound', 'Sonet Shekspira', 'Spanish Leather', 'Starcrest', 'Stop Flirting', 'Strictly Ballroom', 'Sultry Mood', 'Sunny Bubbles', 'Sweet Musette', 'Tempting', 'Terra Rosa', 'Throb', 'Tiger Honey', 'Vasha Velychnist', 'Vechir na Ay-Petri', 'Violet Tiger', 'Visual Arts', 'Warm Embrace', 'Warrior King', 'Wet on Wet', 'World Class', 'World Premier'.

Late-bloom cultivars bloom from May 17 to May 26. There are 60 such cultivars in the collection: 'Alhimik', 'Alpine Region', 'Aphrodisiac', 'Beluye Nochi', 'Bliss Bomb', 'Brandy', 'Chariots of Fire', 'Coastal Mist', 'Coming Up Roses', 'Delfin I Rusalka', 'Depeche Mode', 'Diabolique', 'Elegant Impressions', 'Fashionably Late', 'Fragrant Lilac', 'Gallant Rogue', 'Ginger Swirl', 'Got the Blues', 'Heavenly Rapture', 'Heritage Lace', 'Horatio', 'Hostess Royale', 'In Reverse', 'Instant Hit', 'I'm your Lady', 'Island Sunset', 'Ivory Way', 'Kentucky Woman', 'Khristian Steven', 'King's Tribute', 'Lovelorn', 'Marriage Vows', 'Mashenka', 'Mellow Magic', 'Mountain Majesty', 'Neon Rainbow', 'Overjoyed', 'Paradise', 'Petite Posy', 'Pink Taffeta', 'Power of One', 'Queen of Angels', 'Recherche', 'Ring Around Rosie', 'Rio', 'Romantic Mood', 'Ruffled Ballet', 'Salsa Rio', 'Sea Power', 'Solnechhnuy Veter', 'Sun King', 'Sunkist Delight', 'Supreme Sultan', 'Swingtown', 'Thornbird', 'Tokatee Falls', 'Trevi Fountain', 'Uhtro Tumannoye', 'Vanda Song', 'Vienna Waltz'. The average blooming time of one cultivar from tall group is 21 days. The total blooming duration of collection tall cultivars is 45 days. Thus, the total blooming duration of collection bearded iris cultivars from all three garden groups on the South Coast is about 60 days (Fig. 1), what is of particular interest for use of Iris $\times$ hybrida hort. cultivars for landscaping in the resort area of Crimea.

\begin{tabular}{|c|c|c|c|c|c|c|c|c|c|}
\hline \multirow{3}{*}{$\begin{array}{l}\text { Garden groups of } \\
\text { Iris } \times \text { hybrida hort. }\end{array}$} & \multicolumn{9}{|c|}{ Bloom Season } \\
\hline & \multicolumn{3}{|c|}{ April } & \multicolumn{3}{|c|}{ May } & \multicolumn{3}{|c|}{ June } \\
\hline & I & II & III & I & II & III & I & II & III \\
\hline SDB & & & & & & & & & \\
\hline IB, BB & & & & & & & & & \\
\hline TB & & & & & & & & & \\
\hline $\begin{array}{l}\text { Total blooming } \\
\text { duration }\end{array}$ & & & & & & & & & \\
\hline
\end{tabular}

Fig. 1. Bloom spectrum of Iris $\times$ hybrida hort. cultivars of the NBS - NSC collection.

Analysis of Iris $\times$ hybrida hort. cultivar of the NBS - NSC collection by blooming season showed that the collection includes cultivars of all blooming seasons in each garden group.

In the color of flowers of modern Iris $\times$ hybrida hort. cultivars almost all colors and shades of the spectrum are present, and often a blend of several colors can be observed in one flower. Therefore, most classifications of flower colors developed for ornamental 
plants, based on reference to a color group, for example: white, yellow, blue, etc., do not provide a complete understanding and do not reflect the actual color of the certain iris cultivar. In this case, the most practical and informative is the classification developed by the AIS and built on the principle of a «template» of flower color and on the widespread types of color patterns among irises, which allows you to reflect most fully the color features of a particular cultivar, depending on belonging to a certain type of color class:

- self - the inner (standards) and outer (falls) perianth lobes are colored in the same color;

- bitone or neglecta - standards and falls are colored in tones of the same color, different in intensity;

- reverse bitone - standards and falls of a different tone of the same color, standards are darker than falls;

- bicolor - the upper and lower lobes are colored differently.

Additionally, two-color cultivars are subdivided into the such types as:

- variegate - standards for yellow shades, and falls are colored in the range from brownish to purple;

- amoena - standards are white or almost white, falls are colored;

- reverse amoena - ccolored standards, white falls;

- «Emma Cook» - only a bordure along the edge of the outer perianth lobes is colored;

- «Debby Rairdon» - standards light coloured, falls are white with a wide border of the standard color along the edge of the petal;

- plicata - a type of coloring with a pattern of dots and strokes of dark colors on a light base undertone, the pattern often fuses into a wide band;

- luminata - basic, lighter tone, appears on the standards and along the edge of the outer lobes in the form of the thinnest rim;

- glaciata - a type of coloration similar to plicata, but without dark pigments;

- blend - iridescent color of a flower, combined of two or more colors;

- broken color - "splattered" color, chaotic strokes, strokes of one or more colors.

The studied iris cultivars of the NBS - NSC collection are distributed as follows (Fig. 2):

- 69 cultivars are classified as one-colored («self»), of which 57 tall cultivars ('Apostol', 'Before the Storm', 'Beluye Nochi', 'Beverly Sills', 'Bile Tango', 'Blue Crusader', 'Blue Reflection', 'Breakers', 'Cloud Ballet', 'Coming Up Roses', 'Delta Blues', 'Double Bubble', 'Dusky Challenger', 'Fireside Glow', 'Fringe Benefits', 'Frosting', 'Golden Panther', 'Heavenly Rapture', 'Hollywood Nights', 'Hostess Royale', 'Ironiya Doli', 'Jean Hoffmeister', 'King's Tribute', 'Lake Placid', 'Lotus Land', 'Mallory Kay', 'Martile Rowland', 'Mary Frances', 'Mesmerizer', 'Mountain Majesty', 'Mriya', 'Mulled Wine', 'Nordica', 'Paradise', 'Picasso Moon', 'Pink Sleigh', 'Pink Taffeta', 'Pledge Allegiance', 'Polet Flamingo', 'Queen of Angel', 'Riversong', 'Rolling Thunder', 'Sea Power', 'Silk Romance', 'Silverado', 'Skywalker', 'Song of Norway', 'Soul Music', 'Sultry Mood', 'Superman, 'Swingtown', 'Temple Gold', 'Throb', 'Vasha Velychnist', 'Vienna Waltz', 'Visual Arts', 'Vodogray') 4 medium cultivars ('Amur Batushka', 'Blackbearded', 'Hi', 'Wing My Chimes') and 8 dwarf cultivars ('Bourgeois', 'Carats', 'El Torito', 'Iris Sea', 'Krayina Mandarynok', 'Lace Caper', 'Ornament', 'Snow Season');

- to the color class «bitone» or «neglecta» 43 cultivars are attributed, of which: 35 tall cultivars 'African Mahogany', 'Ayu-Dug', 'Back in Black', 'Black Tie Affair', 'Bright Fire', 'Carl and Sissy', 'Cherry Glen', 'Cross Current', 'Darkside', 'Draco', 'Dynamite', 'Fashionably Late', 'Ghost Train', 'Going Home', 'Hello Darkness', 'Honeymoon Suite', 'Living Free', 'I'm your Lady', 'New Centurion', 'Night Attack', 'Night Game', 'Overjoyed', 'Play with Fire', 'Revolution', 'Royal Crusader', 'Ruffled Ballet', 'Salsa Rio', 'Staroye Zoloto', 'Terra Rosa', 'Tom Johnson', 'Tuscan Villa', 'Victoria Falls', 'Vechir na Ay-Petri', 'Warrior King', 'World 
Premier', 1 cultivar from medium group ('Fruit Cocktail') and 7 dwarf cultivars ('Beau', 'Dark Vader'; 'Demon', 'Double Lament', 'Galleon Gold', 'Little Blackfoot', 'Stockholm');

- to the color class «reverse bitone» - 24 cultivars, of which: 22 tall ('Chariots of Fire', 'Cherub's Smile', 'Crystal Gazer', 'Divine Duchess', 'Fragrant Lilac', 'Horatio', 'Katie Pie', 'Kentucky Woman', 'Lovely Kay', 'Magic Wish', 'Mallow Dramatic', 'Marriage Vows', 'Mellow Magic', 'Nothing But Net', 'Orchid Tapestry', 'Pink Belle', 'Recherche', 'Starcrest', 'Syzokryliy Ptakh', 'Tokatee Falls', 'Vanda Song', 'Warm Embrace') and 2 dwarf cultivars ('Lore' и 'Mrs. Nate Rudolph');

- to the class «bicolor» - 30 cultivars, of which: 25 tall ('Betty Simon', 'Brazilian Holiday', 'Celebration Song', 'Color Splash', 'Dance Hall Dandy', 'Delfin i Rusalka', 'Edith Wolford', 'Electrique', 'English Charm', 'Gallant Rogue', 'Gay Parasol', 'Instant Hit', 'Island Sunset', 'Jurassic Park', 'Kind Hearted', 'Ocelot', 'Olympic Challenge', 'Pagan Mirth', 'Rio', 'Romantic Evening', 'Scarb Neptuna', 'Sonet Shekspira', 'Stairway to Heaven', 'Swedish Modern', 'Sweet Musette') and 5 dwarf ('Chanted', 'Magnetic Storm', 'Pause', 'Ritz', 'What Again');

- to the «variegates» - 5 tall cultivars ('Arabian Story', 'Fiesta Time', 'Gypsy Caravan', 'Supreme Sultan', 'Kapriz');

- to the «amoena» class - 17 cultivars, of which: 15 tall ('Aura Light', 'Champagne Elegance', 'Coffee Whispers', 'Color Magician', 'High Class', 'River Hawk', 'Sertse Okeanu', 'Sharpshooter', 'Sierra Grande', 'Snowmound', 'Snowed In', 'Strictly Ballroom', 'Sugar Magnolia', 'Teamwork', 'World Class'), one medium ('Apricot Frosty') and one dwarf cultivar ('Lilli-Bright');

- to the color class «reverse amoena» - 7 tall cultivars: ('Alpine Region', 'Bliss Bomb', 'Coastal Mist', 'Fogbound', 'In Reverse', 'Ivory Way', 'Santa');

- to the color pattern «Emma Cook» - 1 cultivar from tall group: 'Conjuration';

- to the color pattern «Debby Rairdon» - 12 tall cultivars ('Aphrodisiac', 'Champagne Waltz', 'Ginger Swirl', 'Heritage Lace', 'Limelighter', 'Power of One', 'Romantic Mood', 'Sky Hooks', 'Sunkist Delight', 'Sunny Bubbles', 'Trevi Fountain', 'Mashenka');

- to «plicata» pattern - 23 cultivars, of which: 19 tall ('Acoma', 'Brazen Beauty', 'Classic Look', 'Cozy Calico', 'Emphasis', 'Jumping', 'Kilt Lilt', 'Lovely Dawn', 'Madame Chéreau', 'Morning Mood', 'Petite Posy', 'Quickstep', 'Rancho Rose', 'Rare Treat', 'Secret Melody', 'Sneezy', 'Stop the Music', 'Thin Blue Line', 'Skif'), 2 medium ('Devil's Playground', 'Hot Fudge') and 2 dwarfs ('Skip Stitch', 'Olvia');

- to «luminata» color pattern - 18 cultivars: 14 tall ('About Town', 'Copatonic', 'Cosmic Dance', 'Depeche Mode', 'Excellency', 'Flights of Fancy', 'Got the Blues', 'High Master', 'Honky Tonk Blues', 'Latin Lark', 'Moroccan Magic', 'New Leaf', 'Tempting', 'Twice Told') and 4 dwarf cultivars ('Blue Pools', 'Cat's Eye', 'Inscription', 'Pumpin' Iron');

- to the «glaciata» type - 15 cultivars: 11 tall ('Crystal Glitters', 'Elegant Impressions', 'Lacy Snowflake', 'Lovelorn', 'Luxury Lace', 'Odna Kalyna', 'Pure-as-The', 'Solnechhnuy Veter', 'Sun King', 'Svitanok', 'Tanets Flamingo'), one medium cultivar ('Lemon Pop') and 3 dwarfs ('Little Bev', 'Lumalite', 'Vogni Yalty');

- to the color class «blend» - 29 cultivars were attributed, from which: 23 tall ('Alhimik', 'Brandy', 'Bronzovy Vek', 'Bygone Era', 'Chasing Rainbows', 'Commando', 'Copper and Snow', 'Diabolique', 'Easter Lace', 'Golly Gee Whiz', 'High Roller', 'Juan Valdez', 'Khristian Steven', 'Loonnaya Raduga', 'Navajo Blanket', 'Neon Rainbow', 'Renaissance Fair', 'Seakist', 'Spanish Leather', 'Stop Flirting', 'Thornbird', 'Uhtro Tumannoye', 'Wet on Wet'), 1 medium cultivar ('Zing Me') and 5 dwarf ('Indian PowWow', 'Kiwi Slices', 'Terse Verse', 'Vechory na Khutori', 'Zoryana');

- to the «broken» color class - 7 tall cultivars: 'Cascadian Rhythm', 'Filibuster', 'Ring Around Rosie', 'Skipalong', 'Tiger Honey', 'Violet Tiger', 'Zany'. 


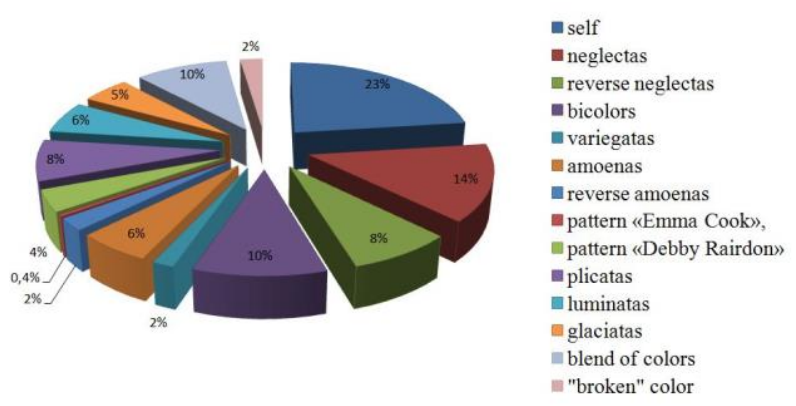

Fig. 2. Definition of Iris $\times$ hybrida hort. cultivars of the NBS - NSC collection by color classes

Thus, the analysis of collection cultivars of Iris $\times$ hybrida hort. according to the color classes showed that all currently defined types of color patterns are represented in the collection of the NBS - NSC, it should also be noted that their quantitative ratio is presented in proportion to the modern world assortment.

\section{Conclusions}

As a result of the studies, the average long-term dates of the blooming beginning of Iris $\times$ hybrida hort. cultivars of the NBS - NSC collection in the conditions of South Coast of Crimea were determined. All collection cultivars are relatively defined by blooming season into: early-bloom, middle-bloom and late-bloom, within their garden groups. The total blooming duration of the studied Iris $\times$ hybrida hort. cultivars of the NBS - NSC collection was determined, which is about 60 days. Also, all collection cultivars are classified by flower color types in accordance with the classification proposed by The American Iris Society (AIS). It was found that in the collection Iris $\times$ hybrida hort. of Nikitsky Botanical Gardens all types of flower color classes from the AIS classification are presented. The data obtained can be used by various specialists in the design of landscaping plantings using Iris $\times$ hybrida hort. cultivars from different garden groups to create long blooming without a break compositions with the widest range of colors and the possibility to create a huge number of unique color spectrums in combination with companion plants.

\section{References}

1. Yu.V Plugatar, Herald of the Russian Academy of Science, 86(2), 120 (2016)

2. Yu.V. Plugatar, Z.K. Klimenko, I.V. Ulanovskaya, V.K. Zykova, L.M. Alexandrova, N.V. Zubkova, N.V. Smykova, S.A. Plugatar, S.A. Plugatar, Z.P. Andriushenkova, Acta Hortic, 1201, 515 (2018)

3. V.K. Zykova, Yu.V. Plugatar, N.V. Zubkova, Z.K. Klimenko, S.A. Plugatar and I.V. Ulanovskaya, Acta Hortic, 1288, 215 (2020)

4. I.V. Ulanovskaya, N.V. Smykova, Z.P. Andriushenkova, Annotated catalog of flowerornamental plants of the Nikitsky Botanical Gardens, 3, 232 (2018)

5. E.I. Datsyuk, Collection of irises of the Botanical Garden of the Moscow State University named after M.V. Lomonosov, 80 (2016)

6. V.V. Kozina, N.A. Slepchenko, Collection of irises in humid subtropics, 3, 60 (2015)

7. L.F. Reshetnikova, Bulletin of KrasGAU, 12, 17 (2015)

8. O.A. Sorokopudova, A.V. Artyukhova, Collection of irises at FGBNU VSTISP, 62, 116 (2017) 
9. I.V. Ulanovskaya, , Subtropical and decorative gardening, 71, 230 (2019)

10. A. L. Sheinina, I.V. Ulanovskaya, Subtropical and ornamental gardening, 73, 181 (2020)

11. D.I. Fursa, S.P. Korsakova, A.G. Amirjanov, V.P. Fursa, Radiation and hydrothermal regime of the Southern coast of Crimea according to the data of the agrometeorological station "Nikitsky Sad" for 1930-2004 and its consideration in the practice of viticulture, 54 (2006)

12. Yu.V. Plugatar, I.V. Ulanovskaya, Results of the introduction of tall bearded iris in Nikitsky Botanical Garden, 204 (2016)

13. V.N. Bylov, Introduction and Selection of Ornamental Plants, 7 (1978)

14. Methodology for State Variety Testing of Agricultural Crops, 6, 222 (1968)

15. Methods of phenological observations in the botanical gardens of the USSR, 136 (1987)

16. The American Iris Society, https://mail.rambler.ru 